Tarih Kültür ve Sanat Araştırmaları Dergisi

Revue des Recherches en Histoire Culture et Art

مجلة البحوث التاريخية و الثقافية والفنية
Vol. 7, No. 3, September 2018

Copyright (C) Karabuk University

http://kutaksam.karabuk.edu.tr

\title{
DOI: 10.7596/taksad.v7i3.1478
}

Citation: Sağır, A. (2018). The Modernization Process of Conservative Female Identity Via Body and Aesthetics: The Âlâ Magazine. Journal of History Culture and Art Research, 7(3), 505-520. doi:http://dx.doi.org/10.7596/taksad.v7i3.1478

\section{The Modernization Process of Conservative Female Identity Via Body and Aesthetics: The Âlâ Magazine}

Adem Sağır ${ }^{1}$

\begin{abstract}
The fundamental argument of the present study was that the conservative female identity was based on the regeneration of body within modern and capitalistic context. The concept of body was focused on because it referred to a context included in interest of power, and it could be reconstructed forms again and again in an observable manner. The present study examined the "ÂLÂ" Magazine that had been published for one year. The main reason for the selection of the "ÂLÂ" Magazine was that it reflected the modernization process of the conservative female identity. In addition, the present study intended to demonstrate how the Magazine represented the stage which the conservative female identity had reached in participating in the public life after the 1980s. A distinctive characteristic of the ÂLÂ Magazine is that it attempts to make the perception of "manhood opening a space for themselves by using political power" a frequently constructed perception in the conservative tradition - inconsistent with the spaces they open for themselves. According to the present study, the conservative female image bears neo-conservative and neo-capitalistic traces while the conservative female identity tries to take itself out of the male power within the triplet of aesthetics, admiration, and beauty.
\end{abstract}

Keywords: Modernization, Conservatism, Woman, ÂLÂ Magazine.

\footnotetext{
${ }^{1}$ Assoc. Prof., Karabuk University, Department of sociology, Turkey. E-mail: ademsagir@karabuk.edu.tr
} 


\section{INTRODUCTION}

Modernization, representing the "rebirth" of Europe, gives birth to conservative thought when its own opposition/criticism is being made. While modernization implies change and transformation, conservatism involves stability and traditional/protective attitudes (Burke, 1999; Kirk, 2001; Heywood, 1992; Parkin, 1997). This nature of conservatism is a resistance for "change" as a social phenomenon which is also the fundamental thesis of modernization. Although the above-mentioned two ways of thinking have different points of origin, they generate "forms of understanding and interpreting" by means of the same "methodological tools". These two opposing thoughts are raised the conflicts of one another and attempt to appropriate the mentality and the pattern of daily habits through the same world of symbols. In this regard, it is possible to argue that both the Turkish modernization and the Turkish conservatism progress by adopting a method like the one in Europe. However, while the Turkish modernization transforms by keeping itself through its own conflicts, the Turkish conservatism follows a conceptual development process where "Islamic" perception is in the foreground and religion is regarded as the primary element (Lewis, 2002; Zürcher, 1993; Marin, 1971; Berkes, 2005).

The phenomenon of "female" was focused on in the present study because it is at the centre of the debates and changes shaped by the modernist thought and the conservative thought. Both thoughts produce " $a$ world of images and perceptions" through symbols. Here, female comes to be at the centre of "power" and "change". Being produced as the "representation of self-confidence" in modernization theses, female is labelled as the "social value equivalent" in conservative theses. The image of self-confident female involves opposing traditional control systems and taking over male-dominated social production stages. The perception of female as the "social value equivalent" is associated with the fact that it is the primary source of social morality. Here, what come into mind are the "roles" provided by "religion" to female and the traditional attitudes" "sanctions that turn into control mechanisms". Surely, such central role provided to female confronts us in the new fields constructed upon the inclusion of capitalism in the agenda of conservative thought. In this way, the basic context where the patterns of daily life are discussed continues to rise over the "female" identity. The control of female in every aspect is important in the conservative thought. Modernization relies on the same context, too. Capitalistic context turns female into a commodity by suggesting that female body should be re-aestheticized. It argues that a mental transformation may be achieved by this means (Arat, 1997; Arat, 2000; Arat, 2001; Göle, 1996; Göle, 1997; Göle, 2002; Kandiyotti, 1998; Kandiyotti, 2001).

Although the present study included all the above-mentioned contexts, it basically claims that conservative female body has been reproduced within modern and capitalistic context. The present study focuses on body because it has been the target of power groups for a very long time and could be defined forms in an observable manner. The present study examines the "ÂLA" Magazine that had been published for three years. The main reason for the selection of this Magazine was that it reflected the modernization process of the "conservative female identity". In addition, the present study intended to demonstrate how the Magazine represented the stage which the conservative female identity had reached in participating in the public life after the 1980s. A distinctive characteristic of the ÂLÂ Magazine is that it expects to make the perception of "manhood opening a space for themselves by using political power" - a frequently emphasized perception in the conservative tradition - inconsistent with the feminine spaces they open for themselves. Surely, these feminine spaces are parallel with the spaces presented by modernization. It was found in the present study that the concepts of "fashion" and "beauty" played a primary role in the presentation of identities. Content analysis technique was employed in the study. The primary categories used in the content and form examination conducted from the first to the tenth issue of the Magazine were mentioned under the title of "body-aesthetics and conservatism". In addition, the line of change found in the content and form examination covering the first issue to the tenth issue of the Magazine made the 
present study distinct in the sense that it carried the modernist and capitalistic traces of the transformation of the mentioned conservative female identity. According to the present study, the conservative female image bears neo-conservative and neo-capitalistic traces while the conservative female identity tries to take itself out of the male power within the triplet of aesthetics, admiration, and beauty based on the "selfsubject" perception of modernism. In this way, the ÂLÂ Magazine organizes daily practices. A new form of presentation of female identity in the public sphere is observed in the axis of modernism.

\section{RESEARCH METHODOLOGY}

Content analysis technique was employed in the present study. This technique was defined by Stacey (2005) as the transformation of qualitative data into quantitative data. According to Smith (1975), content analysis technique involves summarizing, comparing, and categorizing the available data.

Within the framework of content analysis, the first 10 issues of the ÂLÂ Magazine published between 2011 and 2012 were examined. The two reasons for the selection of that Magazine were as follows: (1) it was a female Magazine; (2) it was a conservative Magazine. Surely, the argument that it was a female Magazine was based to the slogan of "Beautiful LifeStyle Magazine" and visuals included in the first eight issues and the slogan of "Magazine of Ladies" appearing in the ninth and tenth issues as well as the fact that it had been published with the name of Aliy'ül Ala for a while. On the other hand, the Magazine was considered a conservative female Magazine because it defined itself in a conservative way and frequently used the concepts of "religion", "tradition", "culture", "scarf", and "hijab" visually. The main intention for the selection of the first 10 issues of the Magazine was to trace the assumption that change in the Magazine went parallel with the change in conservative women. Female and conservatism - two primary categories - were frequently used in the first 10 issues. When 26 issues of the Magazine read backward, the change could be noticed. From $1^{\text {st }}$ issue to $26^{\text {th }}$ issue, the audience of the Magazine extended from "covered" conservative females to a larger population. Though these points were taken into consideration in the present study, the below-mentioned categories were used:

\begin{tabular}{|l|l|}
\hline Body & Visual presentations, brands, technology, luxurious and comfortable life \\
\hline Aesthetics & Beauty, fashion, chicness \\
\hline Conservatism & Culture, tradition, religion, hijab \\
\hline
\end{tabular}

The sub-titles under the title of body were used for categorizing the instruments aimed at organizing daily life through basic visual and verbal "slogans". They were emphasized mainly because they were the most obvious indicators of modernization within conservatism. The categories under the title of aesthetics were aimed at determining the responses of conservative women in the modernization process based on the "female" identity. The category of conservatism was divided into some sub-titles deemed to be important for the present study. The purpose was to make a content analysis based on sub-titles regarding the image of conservative women with reference to the ÂLÂ Magazine.

\section{THE CASE OF THE ÂLÂ MAGAZINE}

Giving coverage to important authors and interviews, the ÂLÂ Magazine, whose first issue was published in June 2011, continues to attract great attention. The interviews and columns prepared with influential names from different circles, along with different views, for over 2 years, re-define the female-fashion Magazine. The ÂLÂ Magazine is a female and fashion Magazine. What makes it different is that its target 
audience is the ladies who have never been determined as target audience by any channels. It is clearly seen today that the target audience firstly addressed by the ÂLÂ Magazine - a female-fashion Magazine has a much larger place in the segment of female products than it has been indicated so far. Knowing the value of discovering new masses and communicating with these masses through correct channels, some important brands have obtained important results thanks to their cooperation with the ÂLÂ Magazine. The $\hat{A} L \hat{A}$ Magazine presents a higher content ratio in comparison to similar female fashion Magazines. With a wide range of materials and columns in its content, it may stand up against the tides of fashion and can be read for a longer time. The limitation of the ratio of pages allocated for advertisement in the Magazine to $35 \%$ of the total content renders advertisement pages more effective.

The ÂLÂ Magazine has drawn the most intense and biggest attention ever in the history of the world press. National and international news channels announced the ÂLÂ Magazine's starting its publication life on news bulletins while some newspapers headlined it or gave it as front-page news. The ÂLÂ Magazine is the sole fashion Magazine which has become a focus of interest in press organs across the world simultaneously with hundreds of news, reviews, special publications, documentaries, and columns prepared about it. Today, the ÂLÂ Magazine is one of the Magazines having biggest number of followers $(\mathbf{1 9 9 , 1 4 4 )}$ on Facebook among all female and fashion Magazines published in Turkish. The Âlâ Loca is a fashionfocused social networking platform unique to ÂLÂ readers where the best properties of similar social networks are offered together. Having started recently, the project has attracted great attention. It is demanded very much. The ÂLÂ Magazine is the first and only Turkish Magazine which has licensed many organizations across the world and is published/about to be published with editions in different languages and countries throughout the world. The Âlâ Indonesia, which is the first edition of the Magazine, has started its publication life officially. Investor applications regarding Malaysia and Dubai editions are still being evaluated.

Since it is a first in Turkey, the ÂLÂ Magazine has started to be discussed in many platforms. While some argue that the Magazine fills an important gap for conservative women, some others think that it may spoil Muslim women. In the present study, both above-mentioned two thoughts were left out. The present study made a content analysis of the Magazine's forms of presenting the "Muslim female" by using a critical discourse. In addition, in the present study, the concept of "conservative Female" identity was used instead of the concept of Muslim woman. One of the most important reasons for this preference was that it was intended to offer a sample typology for the "conservative women" presented in the Magazine. In other words, the study attempted to make a visual presentation of the covered female as a model through practices. Three primary categories in the analysis of the Magazine were body, aesthetics, and conservatism. During the presentation of categories, sub-titles were determined for each category. These sub-titles were "characteristics appreciated" and "characteristics to be avoided". Main categories were evaluated issue by issue in the 10 issues of the Magazine subject to analysis. While the number of pages of the first issue was 112, the following issues consisted of 144, $161,192,177$, and 240 pages. The $10^{\text {th }}$ issue was 304 pages.

\section{Analysis Step 1: The Forms of Presentation of Body and Female Identity}

The publication slogan of the Magazine is "beautiful lifestyle Magazine". Here, the triplet of fashion, beauty, and life comes to the forefront. Life refers to living with "one's own values" while the duality of fashion and beauty represents that fashion re-organizes the life with clothing and consumption. The concept of beauty, on the other hand, implies the rebuilding of body. The instruments of building the body are determined by the trends offered by cosmetics industry and beauty industry. Fashion reflects the valid trends in many fields including but not limited to clothing, accessories, housing, spaces, shoes, and holiday tours.

Since it was the first issue of the Magazine, it invited its readers to present their styles. In this way, it recognized women and aimed to provide them with a desire to "be free". The point of conflict of freedom was the Magazine's duality of fashion and beauty. The Magazine asked women to present their photos taken in clothes and to give information about where they had purchased their clothes. In this way, an 
attempt was made for women to present themselves visually. It was seen that the new image of the conservative woman came together with the image of the woman who was modern in the forms of presenting herself visually. The expression, "all ladies who wish to wear in accordance with hijab" used by the editor in the first issue became one of the primary arguments which the Magazine used for defining its own audience. The presentations aimed at bodybuilding contained a combination of conservative areas, brands, technology, and luxurious and comfortable life besides visual presentations.

The places given under the title of "ÂLÂCadde (ÂLÂStreet)" and the theme shots in such places covered 4 pages in the first issue. However, this number increased gradually in the following issues. The most typical characteristic of the streets in the initial issues was that they represented the spaces where middle-class people were assumed to live. It was seen that the women living in such places wore clothes that were combined harmoniously, had been purchased from local boutiques, did not have any brand value, but were plain in general. It was also attention-grabbing that theme shots were performed with young women. The clothing of some of these women included bracelets and/or dresses designed by themselves. In the first and second issues, the ÂLÂ Cadde made visual presentations of women in the streets of Pendik, Ümraniye, and Avcılar. The $3^{\text {rd }}$ issue, however, presented women from Nişantaşı. The aim was not to show products in terms of their preparation (handmade, designed by themselves, etc.), but to present women as a consumer model. After the $3^{\text {rd }}$ issue, the Ala Cadde shot in Akaretler, Bahariye, Ortaköy, Çınaraltı, Çamlıca, Izmir, Istanbul/Bebek, and Acıbadem. The above-mentioned spaces simply showed the changing social and spatial environment or conditions of the conservative female.

Brands were an important instrument among the forms of bodybuilding. Global brands appeared in the Magazine and were integrated into the modern system in accordance with the female consumer profile based on the consuming role of the conservative female. Another important title where brands were presented in different combinations was "in my bag" that contained visually different products. In the first issue, attention-grabbing products were glasses, cosmetic products, mirrors, wallets, and phones gave place to products were wallets with a, iPhone, MacBook, agendas, Momentous watches, Turkcell VINN, fashion bags, and branded sunglasses which have high brand value in the second issue. Again, in the first issue of $\hat{A} L \hat{A}$, "the secret of Basmala" booklet was given with magazine, but after, in none issues it continued.

Sports and cosmetics industry were presented visually within the context of bodybuilding. For example, sport was presented in the axis of comfort, chicness, and brand. Here, comfort was represented by the fact that different sports activities unique to women and men were presented in separate spaces or through different instruments, chicness was represented by the fact that "the body could be kept at desired sizes", and brand was represented by the fact that sports products with a global brand value were used. In this way, sport was integrated into modern domain and performed by regarding private spaces. Especially in the case of clothes, brands were presented with a social context under the slogan of "the brand of all women who would like to dress well". Shoes, scarfs, bags, coats, and jewelry stood out in the Magazine.

The houses presented visually were equipped with high technology. It was emphasized that the houses represented "comfortable and safe life". When spaces and fashion were mentioned, the reasonability of the prices was emphasized. The above-mentioned comfortableness of spaces was associated with "resting" and "evasion from modern life". The first 5 issues of the Magazine made the emphasis of "cheap but enjoyable". While the first 3 issues of the Magazine did not make any presentation about prices, prices started to be indicated as of the $4^{\text {th }}$ issue. The price range provided in the first four issues was TL 10 to TL 250. The usages of technology in houses were compatible with religious practices. For example, the slogan of "Ramadan Drum on iPhone" was frequently seen in the first issue of the Magazine. A similar form of presentation was used in hijab under the slogan of "A first in Turkey: The scarf keeping cool". Religious practices were combined with consumption patterns within the context of bodybuilding in the "presentation of traditional Ramadan nostalgia in company with the unique Bosporus view". Conservatism 
and bodybuilding were mixed. "Traditional Ottoman cuisine" and "Modern Western cuisine" were presented together in luxurious spaces throughout the Ramadan. "Mobile Sadirvan" attracted attention among the practices that made life easier. It was presented as a necessity of modern life. The form of presentation of the "Mobile Sadirvan (a fountain)" represented an easy and comfortable life:

"Do you have difficulty in performing an ablution? With its clean water reservoir, heating and drying sections, portability and practicality, mobile sadirvan enables you to perform an ablution easily and comfortably, thanks to its tank, even in places where there is no water."

"Silent solutions for bathrooms-inbuilt reservoirs" attracted the attention in terms of the reflection of easy and comfortable life in spaces. In this context, a luxurious and comfortable life was used for modernizing the traditional life of conservative women. Another example in which luxury and comfort were presented along with "plainness" and "traditional codes" was in-house space organization, which was introduced as a "decoration where traditionalism and plainness were offered". An interesting expression seen in the details of introduction was, "a custom manufacturing ten-person carved table and a sixteen-handle luster illuminating it was used in the dining room"

Various items were introduced into the agenda of conservative women when technology and daily practices were combined. For example, the "My Baby\&me" application was offered in iPhone. This application consisted of separate sections for users who were expectant mothers and for users who had just become a mother. Mothers started to use the application by choosing one of the options, "I am pregnant" or "my baby has come into the world" on the splash screen. The slogan of "Hammame", "We are here to keep alive the Turkish bath culture and modern bathing tradition" attracts the attention as a form of space representation where modern and traditional are mixed. Here, the things representing modernism are "hygiene" and "space" organization. In other words, materialism and visuality are modern. Various forms such as massage, sauna, and spa are common in the entire world within the scope of material visuality.

The points representing culture and traditions are predominantly based on cleanliness culture and confidentiality. In the modern sense, some professions are presented as concrete or abstract forms of bodybuilding for women. For example, today, life coaches are also hired by conservative women to organize their life practices. In the Magazine, the title, "To be a woman in the business life" was shaped with the support of an expert psychologist. This is because what matters is the slogan of "let hands touch you". The concepts of "healthy appearance", "dynamic appearance, "attractive appearance", and "self-confidence" are the reflections of the female body touched by correct hands. Thus, "getting rid of wrinkles, stains, and color imbalances, always the best appearance, and self-confidence" become the fundamental arguments of identity for conservative women.

"A bag bought from the Pendik market" can be seen in the arms of a woman in the second issue of the Magazine where a pair of pants bought from the Ümraniye market is visible, too. When the second issue of the Magazine was published, the Magazine had not become "elite" yet. In other words, it still did not address "a specific rich conservative audience". "Henna organization company" included in the third issue of the Magazine was presented as an instrument for conservative women to organize their special occasions. This company was very modern as one of the package services was " 20 Shakira belts". The engagement file included in the $6^{\text {th }}$ issue explains what is to be done by the groom's side and what is to be done by the bride's side in a order. In this way, a planned and modernized practice is offered to the conservative world. All pages of the $10^{\text {th }}$ issue were designed in accordance with the wedding file included in the cover of the issue. The content of the Magazine including the titles of "Recommendations for a happy marriage", "Things to do in wedding feasts", "Wedding spaces", "Bridal dresses", etc. were arranged in accordance with the above-mentioned file. Sports centers, wellness centers, and beauty centers were 
widely presented. In addition, the wedding file included a presentation titled, "Slimming preparations for the wedding":

"Your wedding is approaching. Do you want to feel more energetic? Do you want to reinforce your selfconfidence? Do you want to have a slimmer body? Do you want to be stronger? Do you want to look more beautiful? Do you want to be tighter and fitter in general? Yes, you want surely."

In the fourth issue, the page "Mualla Alışverişte (Mualla Shopping)" presents conservative female as a consumer for pages. Prices were indicated in the sixth issue, too. Mualla attracts attention in different practices in other issues of the Magazine (e.g. "Jewelry design with Mualla"). The statement, "Summer collection minimizing sweating" is noteworthy in that it highlights the importance of hygiene and health in the modern human typology. That brings into question the rebuilding of the body - a new aspect for conservative women. This is because the above-mentioned characteristic turns into a target. Even the association of hair loss with loss of self-confidence is one of the presentations where such reality is visualized. The presentations of "well-groomed feet and nails, and an attractive hand" give rise to the presentation of "a conservative woman who feels good". In this way, it is implied that "the women with well-groomed hands may influence the people around them more easily, feel better, and have higher selfconfidence".

The Magazine has changed its target audience as of the $8^{\text {th }}$ issue. The first 7 issues of the Magazine "attempted to provide conservative women with a visual and identity stance". The $8^{\text {th }}$ issue, on the other hand, introduced marginality. The Magazine no longer limited its target audience to Muslim women. The audience expanded. Conservative women wanted to be marginal, too. The slogan, "Beautiful lifestyle Magazine" was replaced by "The Magazine of ladies" in the $9^{\text {th }}$ and the $10^{\text {th }}$ issues. The new audience was defined as "covered ladies, either veiled or dressed conservatively". In fact, a "state of dissatisfaction" is visible throughout the $10^{\text {th }}$ issue of the Magazine, which can be seen in all advertisements and presentations in the Magazine. This state of dissatisfaction is not perceived negatively, but it refers to the impression created by having lived below the classic and traditional line of religion for a long time. An instantaneous liberation took place, which was caused by the "formation of a neo-conservative bourgeoisie" and the "change of traditional "conservative practices". In this way, sociologically changing conservative woman typology reflected the "desire to go out of the classic conservative female typology".

Some points provided in the Magazine reveals the close link of the Magazine with political transformation. For example, some ministers or deputies from AKP gave interviews to the Magazine. In addition, the wives of leaders were presented to the conservative community as a model. Moreover, the said visual presentations demonstrated that the current discourse of the ruling party gave birth to its own elites, who created spaces for themselves or opened a space for themselves in the existing modern spaces. For instance, they opened wedding spaces unique to themselves in Zeytinburnu as well as manifesting their existence in hotels with the Bosporus view or other luxurious spaces. Although the female body is built upon religion or upon absolute femininity within this context, both religious attitudes and the presentation of women independently of men are disputable. What makes this claim stronger is the fact that the spaces opened for women (fashion and beauty industries being in the first place) were established through men in the first 10 issues of the Magazine. Spaces and social spheres are male-dominated. Thus, it can only be men who open spaces for women. In this regard, it can be said that all those forms of presentation under the "category of body" are used for changing the stance of conservative women from past to present. Published as a Magazine which had been prepared simply and amateurishly in the first issue, the ÂLÂ Magazine addressed people with a middle-income level and partly people with a low-income level. However, the $10^{\text {th }}$ issue of the Magazine included discussions focusing on "conservative women" transformed by money and capital. 
Analysis Step 2: The Forms of Presentation of Aesthetics Although the forms of presentation observed in the first 10 issues of the Magazine are mostly associated with "aesthetics" and "conservatism", the focus is on the category of "body". The matter here is the visual forms presented by the Magazine for conservative women, as provided in the tables above. The category of aesthetics focused on the theme of the transformation of women under three sub-titles: beauty, fashion, and chicness. Here, the concept of beauty was presented within the body of a large industry and was shaped by consuming female typology within the scope of modern social needs. The hadith tells that "Beauty is the light of Allah," and the verse, "Allah is the Light of the heavens and the earth," was used for answering the question of "why a veiled woman should be beautiful". However, the description provided here was based on the distinction between beauty and attractiveness. Those who discredited beauty by associating it with attractiveness were referred to as nihilists. This is because the basic reality emphasized was as follows: "Surely Allah is beautiful and loves who is beautiful. What lies in our power is to satisfy our soul with what is beautiful by focusing on the manifestations of the existence and the beauty of Allah on the earth."

First, the most important emphasis in themes concerning beauty is on the statement, "Beauty is the light of Allah" where it is implied that religion and beauty are integrated into one another. In this way, fashion and chicness are regarded as the forms of presentation of beauty. The presentations of colors, the scent of cosmetics industry, care sets and other products, hygiene, and health serve the same purpose, too. It goes without saying that women are touched by specialized hands here, as was the case in previous bodybuilding forms. For example, specialists make various beauty recommendations for women in the matter of health. The purpose of all these efforts is to create a "charming and rich stance" that visualizes beauty. In-house decoration and food culture are based on the same logic, too. It is noteworthy that "old age" is used for marketing beauty as a field of industry within itself. For example, "stress, air pollution, the harmful rays of the sun, wrinkles, marks, and lack of aliveness (freshness)", regarded as a result of modern life, are actually used as preconditions for the instruments that are to be offered for "avoiding early aging". As a matter of fact, the examined issues of the Magazine mostly cover young girls. Young professionals and students are presented visually. Everybody is young.

The statement, "it is easy to be one of those ladies who does not show their ages by eating more healthily and doing exercises unique to women" encountered in the second issue of the Magazine, is quite important in the sense that it reflects the above-mentioned situation and represents the continuance of confidentiality peculiar to women prescribed by religion. The said preconditions are simply included in the introduction bulletin of the news titled, "vitamin support for the body". They are also reflected in all products or practices of beauty industry presented in the Magazine.

"Adding beauty to beauty" is one of the frequently used arguments. "Anti-wrinkle creams" are offered to conservative women, who are included in the artificial environment of the beauty industry, with various discourses including "without additive", "absolutely organic", "absolutely natural", etc. In this way, it is implied that absolute beauty can be achieved through nature. In this regard, some discourses are produced to announce that products aimed at "supporting, revitalizing and energizing the body and preventing hair loss" are prepared through organic and natural methods. "Bold colors" and assertive dressing put emphasis on "individuality" and "freedom" which are associated with modernism. The individual and entrepreneurial female image featured in the first issues under the slogan of "Reveal the designer inside you" was in the producing position initially. However, the said image was transformed into consuming position in the later issues. The idea reflecting the stance of the Magazine was frequently emphasized in the initial issues: "It is nice to cover oneself! That is my way, my choice, my life, my truth, and my right." As is seen, the conservative female typology re-defines beauty and moves the emphasis on individuality one step forward, and thus wishes to open free spaces for itself in the male-dominated conservative society. In other words, an emphasis is made on going beyond the existing rules. The expression, "Beautiful and delicate styles" 
included in the editor's writing in the $2^{\text {nd }}$ issue of the Magazine is noteworthy in that it reflects the aspects of beauty associated with both fashion and chicness. The main emphasis in the statement, "We, women, all would like to be beautiful" is as follows: "We must wear clothes suitable for our age and our body lines. We cannot wear anything just for keeping up with the fashion". In nested fields, fashion and beauty constitute the focus of reshaping the position of female:

Surely, it is important for me to have beautiful clothes. They should be both modern and suitable for my age and profession. I am not affected by clickety-clack trends very much. What matters is how delicate and elegant my clothes make me look.

Fashion is one of the main forms of presentation in the Magazine. Fashion's forms of combining traditionalism and modernism are remarkable. The definition of hijab fashion confronts us in the $3^{\text {rd }}$ issue of the Magazine: "Hijab does not have any fashion. This is because hijab is not a fashion movement. No one can know that better than us. However, every covered woman has a fashion sense. That is something natural. It is necessary to make a distinction between the said two concepts." The forms of synthesis observed here are either produced or come into being by themselves. Hijab fashion shows, hijab boutiques, and the fact that famous brands turn their hands to hijab designing, which are all seen in the Magazine, are remarkable in terms of the representation of fashion and demonstration of the audience it addresses. Today, conservative women are one of the key themes of the fashion industry. The Magazine's website "yeşiltopuklar (literal meaning: green heels)" is one of the websites through which people follow the fashion. Here, green stands for conservative while heels represent women.

In the definitions of fashion, body is closely associated with identity building processes and the concept of beauty. However, as seen in the subsequent issues of the Magazine, the conservative female identity turns into pastiches in a postmodern mixture. In fact, that represents the rejection of the old. The consumer behavior language of traditional religious codes based on consumption and wastage seems reversed in the case of women here. Fashion is presented from the perspective of beauty. However, there is an intervention in the forms of bodybuilding and in Muslim women's forms of identifying themselves:

First, a woman should consider where she lives and where she wears. She may reflect her own taste in her clothing by deciding on what to wear when going to work or going to a wedding ceremony considering her body structure.

One of the main concerns in the 10 issues of the Magazine is to revise "Muslim women's" forms of identifying themselves. While modernism is redefined, classic senses of conservatism are questioned, because of which the following transformation takes place: "the real success is to realize a new sense of hijab". In this way, the designs of a Dutch, an American, or an English designer for conservative women are legitimized in the axis of chicness and practicality/easiness. These designs may even become the focus of the hijab fashion. This fashion requires big amounts of money, which can only be afforded by the wives or the daughters of the neo-conservative bourgeoisie. In fact, the traces found in the stories of successful young women who have set up their own businesses are remarkable in terms of the questioning of traditional roles. For example, the statement, "one day, she encountered the passport bag of her mother... she thought it was very plain and ugly, so she started to paint it," presented the typology opposing traditional female roles through a simple reality.

Various elements are used in the Magazine for defining conservative women. Some of them are the following titles about the theme of beauty "out of the common", "different and unique", "meticulously prepared", "a simple and modern beauty manifests power", and "every house has a princess". The discourses articulated to the instruments which are used for building a new identity are also the form of presenting a new reality. All the concepts included in discourses are the building stone of the emphasis on individuality and free will. The proposition, "people are welcomed by their appearances and sent by their 
knowledge" is frequently used in the legitimization of fashion even during profession presentations. Therefore, it is implied that in fact "beauty is not a secret", but an "accumulation of knowledge". The promotions of cosmetics products bear the traces of efforts to keep up with the global capitalist system (e.g. "why don't you have the products used by worldwide known names?"). There is an obvious conflict in some statements provided in the Magazine: "For those women who are fond of impressive and eyecatching make-up" vs. "remain chic in plainness". The same kind of conflict is apparent in some specific definitions such as "porcelain baby effect in make-up".

Another area, in which beauty and body gain importance, is the health sector. Besides the proposition of "crazy ideas \& aesthetic results", the issue of "healthy weight loss" is also important for conservative women: Change your lifestyle, find a diet friend, avoid stressful conditions, and keep account of what you eat. A different concept complementing them answers the question of "What should we do to dress chicly?": pay attention to selecting clothes that are suitable for your body lines, age, and position, be attentive to the sizes of the clothes you buy, choose a dress that is appropriate for the place you go to, do not mix together different designs, prefer solid colors, choose your trends carefully, and allocate time for being beautiful and chic. The emphases on health involve all life practices of women (e.g. the titles of "Nourishment during breastfeeding period" and "mother's and baby's psychology in the postnatal period"). "Hand care in busy schedule" is one of the issues highlighted within the scope of "healthy nutrition in the office environment". Touching the body represents not only aesthetic forms but also "magic touches on women". An "adventuresome, elegant, and modern" woman is created with the effect of fashion that contains "sparkling party shoes". The ÂLÂA Magazine even contains "Recommendations for the period after the first sexual intercourse" for conservative women.

Relationships between beauty and spaces attract the attention, too. Now, conservative women are also frequenters of beauty centers. Practices including aesthetic touches on the body such as detox and surgery start to frequently appear on the ÂLÂ Magazine as of the $4^{\text {th }}$ issue. The emphasis made on "privilege" for the Muslim female identity during these presentations is very important because it is possible to see the traces of the fact that the incipient "Muslim bourgeoisie" has started to separate itself from its own circle. "Privilege" is accompanied by "excellent" and "crazy", which also refer to "feeling good". The Magazine even introduces experts for following the fashion and selecting proper colors for different forms of presenting beauty.

Starting out with the slogan of 'Color selection is at no cost, but the cost of wrong color selection is high', COLOURFIT provides color analysis service for those who would like to discover themselves visually. The color analysis offers many opportunities to its customers from the first impression made on people to the productive shopping that will make you find the most suitable clothes for you in a short time.

The fundamental argument used in all 10 issues of the Magazine is the "need for modernization". In this way, it is highlighted that conservative women must experience modernization not only through clothing, fashion, music or daily tastes but also through looking at the world from a different perspective and pioneering innovations.

\section{Analysis Step 3: The Forms of Presentation of Conservatism}

The primary goal of the publication of the ÂLÂ Magazine was to offer a fashion and beauty Magazine aimed at the conservative segment in Turkey - a first in Turkey. Frequently appearing in the first five issues, the sub-titles of "hijab", "the requirements of Islam", "religion", "tradition", and "culture" were determined to be primary categories. The purpose was to investigate where the Magazine could be placed in the axis of conservatism. The description of modernization as a necessity was strengthened and legitimized by such propositions as "The root of Islam is modernity". When appropriate, a four-page writing file titled "Huzur 
İslamda (Peace in Islam)" and the pages of "Ala Ruhaniyet (Ala Spirituality)" cover the above-mentioned subjects.

The obvious emphasis of the first 8 issues published under the slogan of "Beautiful LifeStyle Magazine" was on "hijab" and how life practices with "hijab" could be performed. The statement, "It is nice to be covered" and the experiences about being covered in parallel with it, made it clear that the initial issues of the Magazine did not deal with fashion or beautiful life alone, but tried to fulfill the socio-cultural needs of a large mass. The expression, "All ladies who would like to wear in accordance with hijab", which was encountered in the first issue, is important in that it shows the target audience of the editor. With the slogan, "a need to wear in accordance with body lines and lifestyle", an attempt was made to show both the beauty perception of modernism and religious sensitivity. The expression, "halal certificate for every product that complies with Islamic criteria and human needs" presented as an important religious elements within the scope of the beauty industry is noteworthy in that it shows the conservative concept of the Magazine. In addition, the Magazine gave coverage to the promotion of "non-alcoholic perfume and cosmetic products" with reference to Islamic sensitivities.

Another form of presentation of conservatism in the Magazine is through association with historical accumulations. Many things (e.g. decorations) are presented in the Magazine under the slogan of "our heritage". In this way, the Magazine defines itself as a combination of traditionalism and modernism. For example, Grand Bazaar, The Topkapı Palace, The Sultan Ahmed Mosque, and Turkish Delight are presented within this context. The colors used in clothes are frequently referred to as "Ottoman Colors". The colors of Turkish delight, sugar candy, sorbet, and coffee are associated with fashion. One of the basic textures observed in many issues of the Magazine is the use of "Ottoman concept" for highlighting conservative practices. "Seljuk Collections" is another item of presentation. It involves prayer clothes and abayas dating back to the Ottoman period.

The Magazine takes the concept of fashion out of traditional patterns and redefines it in accordance with the requirements of conservative life. In this regard, the basic perception of the conservative fashion involves "perceiving fashion and life in accordance with one's own values and producing designs in line with it, that is to say, living well without moving away from vital values". The meaning of this perception implied in the Magazine is as follows:

The most important thing to be considered by covered women is to avoid very tight clothes. Since they are covered from head to foot, covered women must avoid exaggeration and prefer plainness. Remember that your clothing is your identity.

Identity is a very important issue for covered women. The perception of "late modernism" was reflected with articles on "the need for modernization". Within this framework, the main themes defining the identity of covered women were as follows " 3 crazy children, a perfect job, and seizing the ideal in both design and life". Thus, "family" and "sexuality" were functioned as two elements defining the female identity. Surely, three words that determine fashion are plainness, comfort, and chicness. The Magazine emphasizes that the clothes designed must comply with hijab before anything else. According to the Magazine, clothes must be conservative as required by religion, but they must also be very chic and suitable for the fashion of the present time. In fact, the redefinition of fashion goes parallel with the criticisms of the conservative thought to modernism. Within this context, it is thought that modernization refers to imitating the West. The statements of a fashion designer engaged in the hijab industry in this matter are noteworthy: 
Our people do not want to be deceived by putting make-up and being polished any longer. They want to act in accordance with their custom and belief. They do not fit in the patterns by others. We cannot consider clothing independently of that. ${ }^{2}$

Traditional codes were used in fashion as a design product. For instance, there was a jewelry collection titled, "Maw/ānā and Shams Collection". Another collection title consisting of religious references was "Mecca and Medina Mysterious Pen Collection". In the marketing of this collection, religious elements were highlighted: "One pen bearing traces of al-Hajar al-Aswad of the Kaaba, and another pen reflecting the door of our prophet Muhammad. A service provided by worldwide known pen company for the sake of the brotherhood of religions."

Sport and beautiful lifestyles were presented along with the title, "Suitable for Islamic traditions". Accessories for sports activities including running, swimming, tennis, walking, etc. that were in accordance with Islamic traditions were highlighted. In addition, it was seen that confidentiality between women and men was preserved in the above-mentioned fields, and sexuality continued to be a taboo. The same taboo was visible in the $6^{\text {th }}$ issue containing the "engagement file" designed within the framework of religious requirements: "Engagement ceremony photos: Cannot covered young ladies have engagement photos? Surely, they can. What matters is to be attentive to the limits established by Allah." The slogan, "Ramadan is brotherhood," is frequently encountered in the Magazine. The goodness of making children fast in Ramadan is mentioned in the chapter titled, "ÂLÂ Children". Some statements summarizing the abovementioned are as follows:

Making children fast in Ramadan is the best way of explaining to them what starvation means, what poverty means, and overconsumption by some people leads to starvation of some other people.

Though holidays were described as the areas where women acted together, holiday packages unique to families were introduced, too. The main purpose was to make a presentation suitable for traditional life practices. Hygiene and health services such as sauna and massage were presented by emphasizing the importance of hygiene in Islam. In addition, they were associated with maintaining the heritage of ancestors. Moreover, it was stressed in the Magazine that the spaces designed for conservative people should have confidential areas for women and men as well as prayer rooms for worshipping comfortably. Another field where traditional codes are redefined, and female roles are presented within the scope of modernism, is the ÂLÂ Law page, which describes the steps for enabling women to stand as self-confident and strong individuals against men. For example, such important titles as "Does a married woman have to gain permission from her husband to set up a commercial enterprise?"; "Who is to get the custody of children after divorcing?"; and "What rights do women have on the subject of heritage?" were presented by the help of specialized lawyers.

Based on the issues reviewed, one of the most distinctive characteristics of the Magazine is that it tries to define the domains which the concept of "love" corresponds to for conservative women. The Magazine sometimes refers to the phenomenon of love possessed by Mawlānā. Sometimes, the themes of harmony and sexual intimacy between spouses are associated with love. For example, the description of the origin of Raviseine - a perfume brand - is interesting: "The Ravi River flows between India and Pakistan. The Seine representing romance and love, on the other hand, is in Paris." Here, an attempt is made to combine modernism represented by Paris with traditionalism represented by Pakistan through the symbolic meanings attributed to perfume. In addition, the fact that the perfume is non-alcoholic, and its name is associated with love, is noteworthy in the sense that it shows the changing world perception of conservative

\footnotetext{
${ }^{2}$ Mehmet Ortakaya, issue: $2, \mathrm{p}: 78$
} 
women. The phenomenon of love between spouses is simply associated with the question, "Are you ready for getting pregnant?" Some other questions involving a concern to feature love are as follows:

Is your womb ready for raising this living being? Do you have enough love to love your baby under all circumstances? Do you love your husband? Do your eyes combine with love? Do your hearts beat for each other? The first condition of having a baby is the love between spouses (Issue, 6).

The distinction made between the concepts of "beauty" and "attractiveness" is remarkable in that it causes questioning the position of Muslim women within conservative patterns:

Another form of oppression has been derived by trying to hide or make invisible even the covered women. They have accepted it as truth that women should dress uniformly and without any aesthetic value. Those who support uniform covering are always ill at ease with seeing the beautiful (Issue, 7).

As the editor of the Magazine changed in the $9^{\text {th }}$ issue, the concept of the Magazine changed, too. The Magazine started to go beyond the emphases of "conservatism", which were seen in the first 8 issues, and turn into a beauty and fashion Magazine. One of the most distinctive themes of the $9^{\text {th }}$ issue was "black psychology in the hijab fashion". The concept suggested that the hijab fashion, which had been ignored for many years, should be included in the agenda of both conservative thought and modernist thought.

Different states across the world directed clothing sector through the concept of fashion until 10 years ago and created a brand-oriented, but not a needs-oriented, economy. Economic crises caused fashion to be re-questioned throughout the world. As a result, consumers started to consume in accordance with their needs, but not the fashion.

An interview statement in the Magazine, "...coming early for her appointment in the beauty center, Ala decides to perform afternoon prayer in the saloon so as not to miss it, thus she makes the best use of the waiting period." is an important indicator of change. The requirements of religion are fulfilled in the spare time within planned and scheduled time. In addition, a mother \& daughter image is used in the advertisement of a hijab brand. The advertisement presents the mother as covered, but the daughter as uncovered. In this way, it is implied that preferences are individual. Covering is presented as an individual preference. It is ignored that men may be decisive in this matter. After then, fashion is presented based on the idea of being admired. Though fashion is regarded as an individual preference and an area of freedom, being admired and forms of presentation have social aspects. Special pages were prepared in accordance with the concept of Mother's Day concerning motherhood - an important representation of traditional female roles - on the $10^{\text {th }}$ issue of the Magazine. However, the gifts presented in the Magazine were not appropriate for the classic conservative mother prototype.

The requirements of Islam were featured under the title, "Recommendation for a happy marriage" included in the wedding file. It was again religious elements that were assumed to direct modern lifestyle. The propositions, "Wedding feasts are aimed at feeding the poor", "Poor people should be invited", and "Wastage should be avoided," may be treated from a religious perspective. However, the spaces presented in the Magazine were not suitable for the concept of "poor" people in terms of class differences. There is a conflict. In fact, the motive to keep alive modernism and traditionalism together brings about a conflict. Likewise, debates on Iftar tents reflect this conflict, too. The advertisements of jewelry, bags, and shoes in the price range of TL 500 to TL 5000 appearing just after the proposition, "Help a person in need with a donation of TL 100" made by a non-governmental organization built upon the idea of guarding poor people also reflect a grave dilemma. 


\section{CONCLUSION}

The ÂLÂ Magazine represents the adaptation of modern consumption patterns to Islamic lifestyle based on the fact that covered women need to modernize, too. Covered woman is envisaged as an individualistic and free-spirited "revolutionary woman" who manifests her beauty beyond "classic conservative patterns". The study dealt with "Cultural Conservative" and left out anything that was about the change or transformation of "Political Conservative". The study gave coverage to "Political Conservative" only in association with the fact that AKP created its own "elites" in the late 2000s during the formation of the "Conservative Bourgeoisie". The main themes included by the ÂLÂ Magazine in the agenda of the "conservative female" typology in the context of need for modernization were happiness, love, art, health, prestige, social relations, aesthetics, career, beauty, and fashion. The role models introduced by the above-mentioned values involved the "experts" of modern system in some cases and well-known people from conservative circle in some other cases. These values were used as important elements of supporting covered women and re-defining "conservative women" as a subject. The most important visual titles of the Magazine were "fashion" and "space". The Magazine aimed to determine the forms presented by the subject described and create new spaces suitable for conservative life or pave the way for entering the existing spaces. In fact, the construction of subject is identical with the building of female body. Here, it combines with the bodybuilding of Kemalist citizenship on the same page. The objectivization of culture is visualized explicitly, and it is emphasized that conservative women may become part of "culture industry". The basic characteristics of the selected issues of the Magazine taken as basis in the present study are as follows:

1. The typology of "covered women" is visually presented in the axis of "fashion" and "beauty".

2. An attempt is made to present the typology of "covered women" in the axis of conservatism and modernity. "Fashion" and "beauty" are the basic instruments used for this purpose. The Magazine traces the efforts of the "neo-conservative bourgeoisie" to integrate with what is modern. "Islamic capital" rising as of the 1990s is influential on the emergence of the neo-conservative bourgeoisie. This Islamic capital turned into "elites" when AKP came to power alone.

3. The target audience of the Magazine turned from all women who described themselves as "covered and beautiful" to "ladies" in the $9^{\text {th }}$ and the $10^{\text {th }}$ issues. Thus, the Magazine started to address the new bourgeoisie emerging in parallel with the political discourse of the ruling party and the people adopting the system of values based on lifestyle. The target of the Magazine came to be the happiness and comfort seeking of the said new classes within the system of values based on lifestyle. The elements setting the said target were the values of happiness, love, art, prestige, social relations, career, fashion, etc. The typology of "covered women" was supported morally. The same typology was presented in a form "strengthening the female identity". In fact, the intention was to redefine "conservative woman" as a subject and to help define the role to be played by her as a subject.

4. The Magazine did not intervene in "conservative woman" as a subject directly. The presentations about the subject involved the proposition, "happiness can be reached only if what is required is fulfilled". What the subject had to do were told to her in every field from fashion and aesthetics to family life and space organization. Those recommendations which were supported visually were expected to direct the subject mentally. The only purpose was to bring success, happiness, and self-confidence to "conservative woman" as a subject.

5. Clothing and space organization were the fields to which the widest coverage was given. The goal in clothing was to determine the forms whereby the new subject would present itself through "fashion" and "beauty" while the goal in space organization was to reform the planned and safe life in accordance with the life requirements of the "neo-conservative bourgeoisie" or enable them to access the existing "bourgeoisie" spaces. 
6. "Bodybuilding" was one of the primary factors influential on the formation of conservative female typology as a subject. All titles of the Magazine from fashion and beauty to aesthetics and hygiene reflected that building process of the Magazine.

7. According to the Magazine, another important domain of life is "money" and "the areas to consume it". The subject may be the master of future and the communities she gets involved in only when she becomes the master of herself, which are also the values of capitalist ethics.

8. One of the concepts emphasized in the Magazine is the self-confidence gained by the subject who spends time and exerts effort for herself. Among the important successes of self-confidence presented in the Magazine are well-established values, emotional strength, physical asset, and personal and social achievements.

In conclusion, necessity was the mother of the mission undertaken by the ÂLÂ Magazine in the beginning. While the Magazine represented a large field including the social, cultural, and spatial needs of conservative women initially, it turned into a fashion and beauty Magazine later on. Thus, it converted the body of conservative woman into a subject of consumption industry. In this regard, the Magazine started to address all "elite" women, but not a segment. The break from the initial line of the Magazine and corrupted anxiety which being have by the conservative women, in the next stage, with the emergence of different women's magazines (Hesna, Aysha, Noura) get a concrete evidence.

\section{REFERENCES}

Arat, Y. (1997). 'The Project of Modernity and Women in Turkey,' in S. Bozdoğan and R. Kasaba (eds) Rethinking Modernity and National Identity in Turkey. Seattle and London: University of Washington Press, 95-112.

Arat, Y. (2000). 'From Emancipation to Liberation: The Changing Role of Women in Turkey's Public Realm,' Journal of International Affairs, 54 (1), 107-125.

Arat, Y. (2001). 'Gender and Citizenship: Considerations of the Turkish Experience,' in S. Joseph and S. Slyomovics (eds) Women and Power in the Middle East. Philadelphia: University of Pennsylvania Press, 159165.

Berkes, Niyazi (2005). Türkiye'de Çağdaşlaşma [Modernization in Turkey] [Ahmet Kuyas (ed.)]. İstanbul, Yapı Kredi Yayınları.

Burke, Edmund (1999). Speech on Fox's East India Bill. In Canavan, F. [ed]. 1999. Select Works of Edmund Burke: A New Imprint of the Payne Edition, Vol. 4. EBook PDF Edition. Indianapolis: Liberty Fund

Friedman, Milton (1962). Capitalism and Freedom, Chicago ve London: The University of Chicago Press.

Gerbic, Philippa \& Stacey, Elizabeth (2005). A Purposive Approach to Content Analysis: Designing Analytical Frameworks, Internet and Higher Education, v8 n1 p45-59.

Göle, Nilüfer (1996). The Forbidden Modern. Ann Arbor: University of Michigan Press. 
Göle, Nilüfer (1997). 'The Quest for the Islamic Self within the Context of Modernity,' in S. Bozdoğan and R. Kasaba (eds) Rethinking Modernity and National Identity in Turkey. Seattle and London: University of Washington Press, 81-94.

Göle, Nilüfer (2002). 'Islam in Public: New Visibilities and New Imaginaries', Public Culture, 14 (1), 173-190. Heywood, Andrew (1992). Political Ideologies: An Introduction, London: Macmillan.

Kandiyoti, Deniz (1998). 'Some Awkward Questions on Women and Modernity in Turkey,' in L. Abu-Lughod (ed) Remaking Women: Feminism and Modernity in the Middle East. New Jersey: Princeton University Press, 270-287.

Kandiyoti, Deniz (2001). 'The Politics of Gender and the Conundrums of Citizenship,' in S. Joseph and S. Slyomovics (eds) Women and Power in the Middle East. Philadelphia: University of Pennsylvania Press, 5258.

Kirk, Russel (2001). The Conservative Mind from Burke to Eliot. Washington DC: Regnery Publishing.

Lewis, Bernard (2002). The Emergence of Modern Turkey. New York \& Oxford, Oxford University Press.

Mardin, Serif (1971). "Ideology and Religion in the Turkish Revolution". International Journal of Middle Eastern Studies, II-3, 202.

Parkin, C. W. (1969). 'Burke and the conservative tradition', in David Thomson (ed), Political Ideas, 118-129. Harmondsworth: Penguin Books.

Perry, Marvin (1985). Western Civilization, Ideas, Politics and Society, Baston, Mass: Houghton Mifflin Company.

Smith, H. W. (1975). Strategies of Social Research: The Methodological Imagination. Englewood Cliffs, NJ: Prentice-Hall.

Zürcher, Erik J. (1993). Turkey: A Modern History. London \& New York, I. B. Tauris \& Co Ltd Publishers. 